The Convergence of Planning and Execution: Improvisation in New Product Development Author(s): Christine Moorman and Anne S. Miner

Source: Journal of Marketing, Vol. 62, No. 3 (Jul., 1998), pp. 1-20

Published by: American Marketing Association

Stable URL: http://www.jstor.org/stable/1251740

Accessed: 23/09/2013 16:38

Your use of the JSTOR archive indicates your acceptance of the Terms \& Conditions of Use, available at http://www.jstor.org/page/info/about/policies/terms.jsp

JSTOR is a not-for-profit service that helps scholars, researchers, and students discover, use, and build upon a wide range of content in a trusted digital archive. We use information technology and tools to increase productivity and facilitate new forms of scholarship. For more information about JSTOR, please contact support@jstor.org. 


\section{The Convergence of Planning and Execution: Improvisation in New Product Development}

The field of marketing strategy often makes the important assumption that marketing strategy should occur by first composing a plan on the basis of a careful review of environmental and firm information and then executing that plan. However, there are cases when the composition and execution of an action converge in time so that, in the limit, they occur simultaneously. The authors define such a convergence as improvisation and develop hypotheses to investigate the conditions in which improvisation is likely to occur and be effective. The authors test these hypotheses in a longitudinal study of new product development activities. Results show that organizational improvisation occurs moderately in organizations and that organizational memory level decreases and environmental turbulence level increases the incidence of improvisation. Results support traditional concerns that improvisation can reduce new product effectiveness but also indicate that environmental and organizational factors can reduce negative effects and sometimes create a positive effect for improvisation. These results suggest that, in some contexts, improvisation may be not only what organizations actually practice but also what they should practice to flourish.

\section{$\mathbf{T}$} he fields of marketing strategy in general and new product development in particular appear to assume that marketing strategy should occur by first composing a plan on the basis of a careful review of environmental and firm information and then executing that plan. In this article, we question this assumption by suggesting that there are cases when the composition and execution of an action converge in time so that, in the limit, they occur simultaneously. We define such a convergence of composition and execution as improvisation and suggest that the narrower the time gap between composing and performing (or planning and implementation), the more that act is improvisational.

Marketing literature, similar to many businesses fields, has paid relatively little attention to extemporaneous behavior and has taken a rather strong stand in favor of marketing planning, especially of a formal type (e.g., Armstrong 1982; Sinha 1990). Although there have been important exceptions in marketing and related literature (Holbrook 1995; Hutt, Reingen, and Ronchetto 1988; March and Simon 1958; Mintzberg 1994), a rational planning norm has become deeply entrenched. Table 1 overviews a sample of marketing and product strategy textbooks that indicates a fairly uniform acceptance of the be-

Christine Moorman is Associate Professor of Marketing and Anne S. Miner is Associate Professor of Management, Graduate School of Business, University of Wisconsin-Madison. This research benefited from the support of Paula Bassoff, Aric Rindfleisch, Bob Drane, Gabor Kemeney, Stephanie Dixon, David Robinson, and Rona Velte and the comments of Peter Dickson, Kathy Eisenhardt, Mary Jo Hatch, Jan Heide, and Thekla Rura on previous versions of the article. National Science Foundation Grant SBR-9410419, the Marketing Science Institute, and the University of Wisconsin School of Business Sabbatical Fund have supported this research. lief that marketing strategies should, in general, first be formulated and then implemented.

Much of the research literature in marketing shares this view. For example, a review of published articles cited in a recent special issue of the Journal of Marketing Research on innovation and new products reveals a tendency to view planning as the accepted norm while acknowledging that business environments are becoming increasingly dynamic (Wind and Mahajan 1997). Studies there and elsewhere suggest that product development cycle times are faster (Griffin 1997), failure rates lower (Cooper and Kleinschmidt 1986; Montoya-Weiss and Calatone 1994), financial returns greater (Ittner and Larcker 1997; Song and Parry 1997), and innovation levels higher (Olson, Walker, and Ruekert 1995) when companies take certain advanced planning steps.

Our purpose in this article is not to detract from the value of planning. We believe that planning is an important aspect of effective marketing management and decision making. However, prior theory also points to several reasons why improvisation sometimes can be a valuable and effective approach to marketing action. First, improvisation can be an effective choice when a firm faces environmental turbulence that requires action in a time frame that is shorter than a regular planning cycle. For example, Egge (1986) describes how a salesperson might improvise when immediate action is required in the face of changing client demands; Dickson (1997) suggests that fast learning and adaption without much advance planning are important to firm survival; Moorman and Miner (1995) describe how a team improvised a new product formula in response to a surprise introduction of a competitive product; and Eisenhardt and Tabrizi (1995) find that an experiential strategy involving improvisation works better in the computer industry when product development must operate within the high level of 
Aaker (1988)

Boyd and Walker (1990)

Boyd, Walker and Larréché (1998)

Cravens and Lamb (1993)

Dalrymple and Parsons (1990)

Day (1990)

Dickson (1997)

Jain (1997)

Kerin and

Peterson (1995)

Kotler (1994)

Lehmann and Winer (1994)

Peter and Donnelly (1998)

Quelch, Dolan, and Kosnik (1993)
Figure 2-1 provides an overview of the strategic market management process. This figure shows external and self-analysis occurring first, followed by strategy identification and selection, which includes, in order: mission specification, strategic alternative identification, strategy selection, implementation, and evaluation (p. 22).

The authors define strategy as "a fundamental pattern of present and planned objectives, resource deployments, and interactions of an organization with markets, competitors, and other environmental factors" (p. 43). This definition emphasizes planning, or the setting of objectives, as an integral part of strategy formulation.

Exhibit 1-7 depicts the marketing management process as moving from analysis to the formulation of strategic marketing programs, and finally to the implementation and control of such programs (p. 16).

"Strategic planning is a continuing cycle of making plans, launching them, tracking performance, identifying performance gaps, and then initiating problem-solving actions" (p. 688). The authors provide eight comprehensive steps in preparing and implementing the strategic marketing plan (Exhibit 1, p. 688).

"Once marketing plans have been prepared, they are used to guide field marketing activities for the planning period." Marketing performance should be monitored to compare results with the goals of the marketing plan (p. 822).

Although Day incorporates both bottom-up and top-down approaches to decision making, the implicit strategy model in his book is that strategic planning precedes implementation and execution of the plan. This is evidenced in Figure 2-1 and because implementation is not an important part of the text; instead, the emphasis is on strategy development.

Defines improvisation as “impromptu action” and notes (p. 37), "An organization's survival depends on its ability to learn and adapt quickly; in practice, this means that plans often must be altered at the very time they are being implemented." He sums up his position on improvisation when he notes (p. 399), "In summary, the ying and the yang of product development is the planning discipline of up-front continuous environmental analysis, targeting/positioning, product specification, judicious stage-gate reviews of the emerging product's fit, feasibility, and estimated profitability combined with the creative improvisation from a team's many iterations of prototype design and testing."

Exhibit 2-4 depicts the process of strategic marketing, which involves a clear separation of strategy development and strategy implementation (p. 33).

"The selection of a course of action must be followed by development of a plan for its implementation. Simply deciding what to do will not make it happen. The execution phase is critical, and planning for it forces [you] to consider source allocation and timing questions" (pp. 35-36).

Figure 3-1 (p. 63) shows a linear process moving from planning to implementing to controlling. The process has feedback loops from controlling back to implementation and planning.

"In general, the planning process works as shown in Figure 2-4. Whereas the collection and analysis of data and the development of product strategies takes place in a limited time frame, there is no beginning or ending to the planning process as a whole. The formal part of the process is followed by implementation, during which programs such as distribution, promotion, advertising, and the like are executed. Monitoring and evaluating both the performance of the plan and changes in competition and customers in the external environment are also continuous tasks. This information feeds back to the formal planning part of the process" (p. 31).

"The organization gathers information about the changing elements of its environment.... This information is useful in aiding the organization to adapt better to these changes through the process of strategic planning. The strategic plan(s) and supporting plan are then implemented in the environment" (p. 10).

"The marketing process can be divided in several different ways. (Our) conceptualization of marketing tasks is: (1) marketing research, (2) marketing strategic formulation, (3) marketing planning, programming, and budgeting, and (4) marketing organization and implementation" (p. 9). 
uncertainty created by quickly changing markets and technologies.

Second, improvisation might be prompted when planning has not provided all the details or tactics of implementation. Quinn's $(1980,1986)$ investigation of ten large organizations finds that these organizations refined their general strategic course incrementally as new information emerged from the environment. Likewise, researchers have reported that many tactical marketing decisions are not included in marketing plans (Cossé and Swan 1983; Sutton 1990).

These reasons for improvisation are consistent with a more behaviorally based view of strategy development, which asserts that organizational ${ }^{1}$ action often occurs without much advance planning (Cohen, March, and Olsen 1972; Cyert and March 1992; Pfeffer 1982; Weick 1979). This research tradition therefore tends to focus on the behavioral dynamics that produce effective action as opposed to documenting whether organizations adhere to normative models of action (Burgelman 1983; Miner 1987, 1990; Mintzberg and McHugh 1985).

Several marketing scholars have followed in this tradition and suggest that there is a gap between normative and descriptive accounts of marketing strategy (Anderson 1982; Day and Wensley 1983; Wind and Robertson 1983). For example, Hutt, Reingen, and Ronchetto (1988) find that unplanned, innovative new product activities, or autonomous strategic behavior (Burgelman 1983), occur in organizations and that marketing plays a key role in such activities by virtue of its boundary-spanning and product-championing behavior.

Therefore, there is a precedent both in and outside marketing literature for examining the topic of unplanned, innovative behavior. However, there are few cases of systematic empirical investigations of improvisation specifically. Outside marketing, research has tended to focus on depth analysis of single improvisations by persons, groups, or organizations (e.g., Hutchins 1991; Preston 1991; Weick 1993a). In marketing, research has been qualitative (Moorman and Miner 1995) or focused more broadly on innovation (Hutt, Reingen, and Ronchetto 1988).

We build on these important observations by developing and systematically testing a framework that studies the incidence of improvisation in new product activities. Because improvisation is a type of innovative behavior that often involves fast learning (Eisenhardt and Tabrizi 1995), we draw on existing literature on innovation and learning to make our case for why certain environmental and organizational factors are important to improvisation. However, we are also careful to show that improvisation is distinct from innovation and that these factors provide special insight into improvisation, given its extemporaneous nature.

In addition to examining the incidence of improvisation, we also seek to understand the conditions in which im-

IAlthough we use the term organizational throughout this article, we do not mean to suggest that the focal action is necessarily at the overall organizational level. In general, measurement of organizational phenomena occurs within a strategic business unit (Eisenhardt and Tabrizi 1995). provisation is effective. As we have reviewed previously, one research tradition is based on the belief that a lack of advance planning reduces the chances of a firm's success (e.g., Cooper and Kleinschmit 1986, 1987). Other research, however, has found success stories when organizations have improvised. For example, Mintzberg and McHugh (1985) detail the effective improvisations of the National Film Board of Canada; Preston (1991) describes a group of managers that improvises an effective solution to a manufacturing plant strike; Eisenhardt and Tabrizi (1995) show that an experiential approach involving improvisation accelerates product development in the computer industry; Weick (1993a) describes the effective improvisations several firefighters used to escape the firestorm at Mann Gulch; and Pascale's (1984) portrait of Honda's successful introduction of its $50 \mathrm{cc}$ bikes into the U.S. market involves improvisation.

It is not our goal to suggest that improvisation inherently is either helpful or harmful for organizations. Instead, we study the literature on improvisation to uncover the systematic influence of various factors that affect whether improvisation hurts or helps organizations. We seek to supplement current knowledge regarding the types of environmental conditions and organizational competencies that might determine the effectiveness of improvisation. Therefore, our objectives are twofold: (1) to investigate the conditions in which improvisation is likely to occur and (2) to examine the conditions in which improvisation is likely to be effective.

\section{Improvisation}

\section{Definition and Discrimination from Related Constructs}

Our review of prior research suggests that an assessment of whether improvisation occurs requires looking not just at what happens, but also at the temporal order in which it happens (see also Moorman and Miner 1998). Observers typically assume that composition or planning occurs first and is followed at a later time by implementation or execution. In improvisation, the time gap between these events narrows so that, in the limit, composition converges with execution (Weick 1993a). Therefore, the more proximate the design and implementation of an activity in time, the more that activity is improvisational.

This definition is consistent with core conceptualizations of improvisation in several bodies of literature. For example, improvisation is referred to as "thinking in the midst of action" in education (Irby 1992, p. 630), occurring when "acts of composing and performing are inseparable" in communication (Bastien and Hostager 1992, p. 95), "reading and reacting in parallel" in sports psychology (Bjurwill 1993, p. 1383), "real-time composition" (Pressing 1984, p. 142; Pressing 1988) and "making decisions affecting the composition of music during its performance" (Solomon 1986, p. 226) in music, and representing "no split between design and production" in organizational studies (Weick 1993a, p. 6). By focusing on the simultaneity of events, this research also follows in the tradition of organizational theo- 
ries of temporal order (Cohen, March, and Olsen 1972; Van de Ven 1986, 1993).

Improvisation also can be distinguished from other, related concepts in literature (Moorman and Miner 1998). Most important, we argue that improvisation is a special case of intraorganizational innovation, which is defined as deviation from existing practices or knowledge (Rogers 1983; Zaltman, Duncan, and Holbek 1973). All improvisation, by definition, involves some degree of innovation because improvisation involves the creation of action outside current plans and routines. There are many other kinds of innovation beyond improvisation, however. For example, if an organization innovates a new way to distribute a product by analyzing customer needs, gathering facts, and planning a new channel, the organization has innovated but not improvised. In addition, though all improvisation has some degree of innovation, the degree of innovativeness can vary enormously. For example, some improvisations are very innovative and deviate far from existing routines, such as in the case of "free jazz" (Berliner 1994) or of NASA teams improvising to rescue Apollo XIII by making radical use of objects outside prior routines or structures (Lovell and Kluger 1995). Other improvisations only involve minor deviations from current routines, such as when musicians add embellishments to existing melodies (Bailey 1980) or product development teams add features to existing products (Miner, Moorman, and Bassoff 1997).

Improvisation is also distinct from other constructs important to strategic firm behavior, such as adaptation, learning, and opportunism. First, improvisation is distinct from adaptation, which involves the adjustment of a system to external conditions (Campbell 1989). We argue that adaptation does not necessarily invoke improvisational action by organizations. Instead, adaptation can be achieved in a variety of ways, including both preplanning and improvisation. Second, if learning is a process that requires the discovery, retention, and exploitation of stored knowledge, including information or behavioral routines (Huber 1991; Levitt and March 1988), then not all learning is improvisation. For example, learning might involve a carefully preplanned experiment whose results are recorded and interpreted and that requires no improvisation whatsoever. Third, when organizations are described as opportunistic, they are likely to seize attractive, unexpected developments or opportunities proactively (Aaker 1988; Miner 1987; Mintzberg and McHugh 1985; Quinn 1980, 1986). ${ }^{2}$ As with the other discrimination variables, opportunism can be achieved through means other than improvisation, such as developing a plan. In addition, improvisation sometimes arises in disastrous situations and involves overcoming obstacles more than it does taking advantage of unexpected opportunities.

\section{Organizational Improvisation}

Many observers have described improvisation by individuals. For example, people have described ways in which individual actors, athletes, therapists, musicians, or teachers

${ }^{2}$ This view of opportunism as benign (Miner 1987, p. 334) omits the definition of opportunism as "self-seeking with guile" that Williamson (1975) proposes. improvise in different settings. Weick (1993a) describes in detail the improvisational and other actions of individual firefighters in a disastrous firetrap, though he also explores team aspects of the situation.

In addition to individual improvisation, observers have emphasized that collective improvisation also occurs (Crossan and Sorrenti 1997; Preston 1991; Weick 1993a, b, c). One detailed report (Hutchins 1991) describes actions taken by the crew of a ship whose navigational system had broken to make their way into a harbor. To avoid danger, the crew members called out estimates of coordinates, calculated subparts of the data needed to make navigational choices, and communicated partial information to one another repeatedly. Although a transcript of their interactions indicates that no one crew member understood the complete system they had improvised or exactly why they were succeeding, the crew developed a set of routines that worked to get the ship into the harbor.

We follow this approach by focusing on organizational improvisation, which includes improvisation by groups, departments, or whole organizations. Many observers assume that such entities generate and execute plans. Therefore, we attempt to study them as carrying out these activities either in sequence or nearly simultaneously, and thus improvising or not. Although the nature of collective or organizational features remains contentious (Argyris and Schön 1978; Walsh 1995), we follow other work describing organizational features, such as culture (Deshpandé, Farley, and Webster 1993; Deshpandé and Webster 1989), organizational information routines (Jaworski and Kohli 1993; Kohli and Jaworski 1990; Moorman 1995), and memory (Cohen 1991; Huber 1991; Moorman and Miner 1997; Walsh 1995; Walsh and Ungson 1991). To highlight the nature of organizational improvisation, Appendix A provides examples of firms varying in the degree of improvisation in their new product activities.

Prior research suggests that interactions among persons who are improvising frequently produces collective improvisation. In an improvisational theatrical group, for example, one actor might make a comment, to which a second will respond with an association between the comment and another topic, and then a third actor might link these issues to a third, inclusive topic (Crossan and Sorrenti 1997; Mangham 1986; Spolin 1963). The theatrical group did not plan the scene in advance, and the pattern that arises is not a simple sum of independent improvisational actions but a collective system of interaction that creates and enacts the scene simultaneously.

The idea that a system of interaction can produce collective improvisation also is supported by Hutchins's (1991) case study of the crew improvising a solution to their ship's failed navigation system and by Barley's (1986) observation that hospital technicians and radiologists jointly improvised routines in response to new technology. In a powerful set of case studies displaying improvisation, Dougherty (1992) describes new product development teams interacting in ways that do not follow established organizational routines and notes, "Successful developers violated ... routines and created a new social order for their collaborative efforts. They developed mutually adaptive interactions in which knowledge of the work was developed

\section{4 / Journal of Marketing, July 1998}


as the work unfolded" (p. 192). In one example, Dougherty (1992) cites the case of SALECO's development team, which broke routines by using products assembled from off-the-shelf parts purchased externally rather than those manufactured in-house. This team also opted to introduce a software product with some bugs in it instead of holding to the routine of perfect quality control, because they realized that users cared more about the number of applications than they did about perfect operation.

These examples and others suggest that collective improvisation often builds on and incorporates individual improvisation. However, individual improvisation alone is not sufficient for collective improvisation. Instead, the joint activities of individual people create a collective system of improvisational action. In addition, there are occasions in which a person's behavior, planned or improvisational, sparks collective activities that are improvisational in nature (Burgelman 1983; Hutt, Reingen, and Ronchetto 1988). For example, in the case of planned or deliberate individual behavior creating organizational improvisation, Eisenhardt and Tabrizi (1995) find that leaders' deliberate behaviors played an important role in speeding the development of highly iterative and experiential new product development (see also Miner 1987; Quinn 1986). Other times, collective improvisation results from individual behavior that is itself highly extemporaneous (Mintzberg and McHugh 1985). In either case, the individual improvisation must move to the organizational level for collective improvisation to occur. In short, there must be an element of collective design and execution.

\section{Conceptual Framework}

Having established the nature of improvisation and its potential importance to contemporary organizations, we develop arguments about the incidence and effectiveness of improvisation in organizations.

\section{Factors Influencing the Incidence of Improvisation}

Theory and prior research suggest many factors that might enhance the chances that improvisation will occur in organizational activity. First, improvisation might occur because of a lack of organizational discipline, so that an organization makes up new plans as it goes along simply because it lacks the rigor to follow prior plans (Cooper and Kleinschmidt 1986; Etzioni 1964). Second, an organization deliberately might encourage spontaneous activities that are inconsistent with prior plans or activities, suggesting that it has "learned to improvise" (Burgelman 1983; Hutt, Reingen, and Ronchetto 1988; March 1976; Moorman and Miner 1998). Third, improvisation might occur within what we call the logic of responsiveness. This stream of thinking suggests that organizations sometimes face unexpected jolts or surprises that make prior plans irrelevant or incomplete in important ways. Such jolts often are coupled with a context in which it is difficult to refrain from taking action or complete a new planning cycle before taking action. Weick's (1993a) work on improvisation by firefighters, Preston's (1991) example of improvised decision making during a strike, and Eisenhardt and Tabrizi's (1995) findings about improvisa- tional styles in product development all focus on settings in which unexpected stimuli create the need for organizational action but also weaken the effectiveness of prior planning. The central premise of this line of thinking is that improvisation might have special value in these circumstances (Miner 1987). We formalize the logic of this stream of thought in the next three hypotheses, which are shown in Figure 1 .

The impact of environmental turbulence. When the environment in which an organization operates experiences a lot of change, the organization has several choices. It can ignore external demands or shocks that suggest the need to change plans and continue with previously planned activities; it can attempt to speed up its planning and execution cycles so that they remain distinct but happen more quickly (Eisenhardt and Tabrizi 1995); or it can move toward an improvisational approach that merges planning and execution processes.

In some cases, fast-changing environments can destroy the value of existing competencies (Tushman and Anderson 1986). In such circumstances, organizations might find it necessary to improvise or compose new behaviors while executing them. As Weick $(1979$, p. 102) states, "If there exists a truly novel situation, one in which there is no analogous experience in the past, then the only thing the person can do is act." In other words, strategy implementation actually can be "made up as firms go along" (Weick 1993c, p. 2). Consistent with this view, organizational scholars have argued that the increased pace of competition might require organizations to develop an improvisational competency to prosper (Brown and Eisenhardt 1995; Eisenhardt and Tabrizi 1995; Mintzberg and McHugh 1985). The basic logic here is that exogenous shocks or demands come along more rapidly than an organization can anticipate, and organizations often respond to such situations by improvising rather than not responding. We hypothesize that

$\mathrm{H}_{1}$ : The greater the level of environmental turbulence, the greater the incidence of organizational improvisation in new product actions.

The impact of real-time organizational information flows. The logic of responsiveness implies that awareness of external or internal surprises can trigger organizational improvisation. Therefore, the more an organization maintains access to information flows, the more likely it is to become aware of either external shocks or unexpected internal surprises.

Some literature points to a particular type of information flow-that which flows in real-time interaction among group members-as an important stimulus to group improvisation. Bastien and Hostager (1988), for example, document the nonverbal cues band members give one another in jazz improvisations. Likewise, Spolin (1963) points to the criticality of real-time cues flowing among improvisational theater players as their scenes unfold. In addition, real-time information flows between the actors and the audience not only inform but also stimulate specific improvisational activities. For example, a troupe might extend an improvisational skit, spurred by real-time audience reactions.

We define real-time information flows as those that occur during or immediately prior to an action (Eisenhardt 


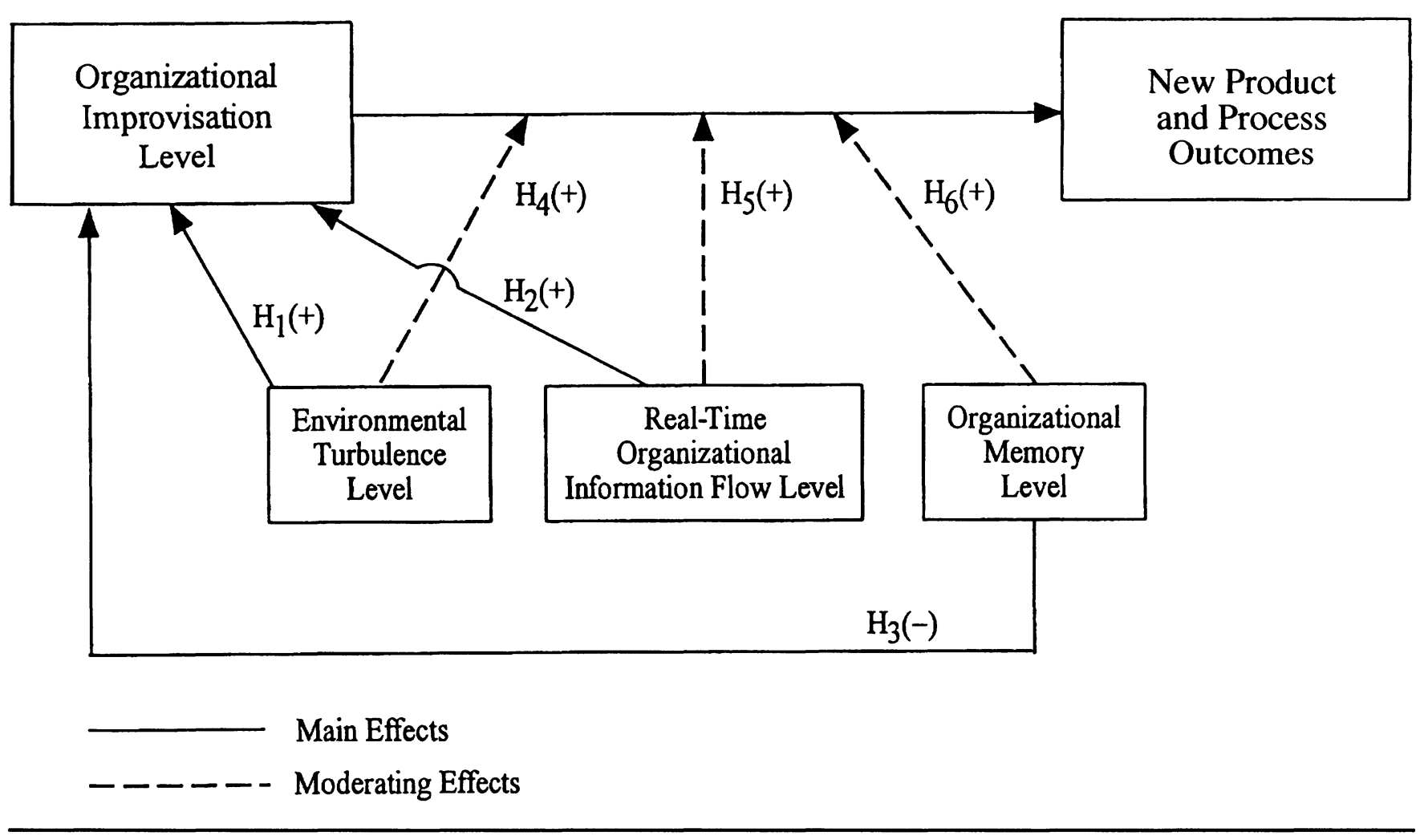

1989). These flows contrast to information processes that occur well in advance of an action or that are used after an action to evaluate its impact. Real-time information flows are likely to occur in face-to-face interactions and electronic communications, in which there are few time delays and great opportunities for feedback (Eisenhardt 1989; Sproull and Keisler 1991). Therefore, team meetings in which decisions and interpretations are made and behaviors are carried out are often sources of real-time information flows (Dickson 1997).

Using our logic of responsiveness, we predict that heavier real-time information flows will create more possibilities for organizations to be exposed to unexpected information that invites improvised action. We make this prediction for three reasons. First, real-time information is, by definition, timely. Therefore, unlike information that may get to a decision maker too late for action to be taken, real-time information is inherently more actionable. Second, because it occurs during or immediately prior to an action, real-time information has an urgency to it that is likely to evoke immediate responses, which probably cannot be planned. Third, real-time information flows are more novel because they evolve in a more random manner than non-real-time information. For example, real-time information flows during a meeting would be more likely to involve unexpected information than those emanating from a series of written memos. These qualities provide greater potential for improvisational activity. We predict that
$\mathrm{H}_{2}$ : The greater the level of real-time organizational information flows, the greater the incidence of organizational improvisation in new product actions.

The impact of organizational memory. We have suggested that real-time information about internal or external surprises might enhance the chances that improvisation will occur. In contrast, prior work suggests that stored information, in the form of organizational memory, will reduce these chances. As with organizational improvisation, there is some disagreement regarding whether organizations store information in memory as people do. However, there is a growing sense across disciplines that organizations have frames of reference, routines, and structures that reflect the presence of stored knowledge (for a review of this literature, see Cohen 1991; Cohen and Bacdayan 1994; Cohen and Levinthal 1990; Walsh 1995; Walsh and Ungson 1991; Winter 1987). We adopt that perspective in this article but focus on the level of knowledge contained in an organization's memory, which we previously have defined as collectively held beliefs, behaviors, or physical artifacts (Moorman and Miner 1997, p. 93). Therefore, a high level of organizational memory would be present when a project or action phase represents familiar territory, a new product requires only a modest change in an old project, the technological or customer basis for the new product is part of the firm's longstanding repertoire, there are well-established team routines because the duration of the team members' service is high, or a particular action phase (e.g., prototype development) is 
an established firm-level competency (Moorman and Miner 1997).

By definition, organizational memory represents learned ways of thinking and behaving. As such, memory often is activated automatically in certain situations. For example, firms tend to develop line extensions of existing products rather than create completely new ones (Andrews and Smith 1996). Firms also tend to use well-developed routines and processes for developing and introducing new products (Day 1994; Leonard-Barton 1992; March 1991; Moorman 1995; Moorman and Miner 1997) and therefore learn fewer new routines (Sinkula 1994).

Preston (1991, p. 89) discusses the negative effect that prior memory is likely to have on the incidence of improvisation, noting: "In the case of these familiar situations ... the scope for improvisation is more constrained." Likewise, jazz musicians have commented on the paradox of needing to learn great artists' works to improvise well but then finding themselves trapped by this learning (Weick 1993c). As Berliner (1994, p. 206) notes, "In one of the greatest ironies associated with improvisation, as soon as artists complete the rigorous practice required to place a vocabulary pattern into their larger store, they must guard against its habituated and uninspired use."

The tendency for existing knowledge to restrict the range of options is a common challenge for innovation of all types but is an especially strong impediment to improvisational action. In improvisation, the time between composing and executing is small and/or nonexistent. We suggest that the pressure of fast action enhances the possibility that an organization will rely on existing routines, regardless of whether a learned response is warranted. Therefore, we hypothesize that

$\mathrm{H}_{3}$ : The greater the organizational memory, the lower the incidence of organizational improvisation in new product actions.

\section{Factors Influencing the Effectiveness of Improvisation}

In the prior section, we highlighted three factors that we predict will influence the incidence of improvisation. The value or effectiveness of that improvisation, once engaged in by a firm, is another matter. There has been a tendency to think of improvisation as either helpful or hurtful to organizations, as we noted previously. We address these equivocal perspectives by identifying selected factors that moderate the impact of improvisation and determine whether improvisation benefits or hurts organizations. We begin our discussion of these factors by identifying the new product development outcomes we believe might be potentially associated with improvisation. We then consider how the same important informational factors that influence the incidence of improvisation also might moderate its impact on these outcomes. This dual role creates several potential trade-offs for organizations to manage.

Focal new product development outcomes. There are several outcomes typically associated with improvisation (Brown and Eisenhardt 1995; Eisenhardt and Tabrizi 1995;
Preston 1991; Weick 1993a, c, 1996). For example, when improvisation works well, it can produce aesthetically pleasing outcomes in a theatrical or musical setting (Hatch 1997). Likewise, it can provide instrumental value for organizations or groups by solving problems or capitalizing on unique opportunities (Weick 1993b, 1996).

Here, we investigate several types of outcomes that focus on organizational effectiveness, which we define as the degree to which an action achieves instrumental outcomes of value for a firm (Walker and Ruekert 1987). We focus on two types of effectiveness outcomes: product and process.

For product outcomes, we investigate design effectiveness, defined as the degree to which new product features are high quality and high performance, and market effectiveness, defined as the degree to which the new product meets the demands of target customers. An organizational example of these outcomes might be a product development team's improvisation of a new casing unit for a previously unprotected part on a commercial research instrument. Effective improvisation of the unit would require that the materials and size of the casing match each other and reflect a quality level (design effectiveness), and that the unit fit the customer's needs so that the product works in the settings for which it was designed (market effectiveness).

Improvisation not only influences the effectiveness of a new product, but, we reasoned, it also could affect the effectiveness of the new product development process. Two indicators of term process effectiveness seemed particularly important: team functioning, which refers to the team's commitment level to the project, and team learning, the level of knowledge the team gains in performing a new product action. Finally, the effectiveness of new product development processes is also, to some degree, revealed in the cost efficiency (financial investment level) and time efficiency (time investment level). ${ }^{3}$ The next three sections relate improvisation to these product and process outcomes.

The moderating impact of environmental turbulence. We predict that the rate of environmental turbulence will moderate the improvisation-effectiveness relationship, because it shifts the advantages and disadvantages of formal planning versus improvisation. If, for example, an organization's environment is stable and continuous, planning in advance of action offers that organization many possible advantages (e.g., Armstrong 1982; Miller and Cardinal 1994). The organization can take the time to do complete planning, knowing that the assumptions and facts guiding the plans probably will still hold at the end of the planning cycle. Thus, the organization can harvest the tremendous coordination and control benefits of good planning, including avoiding inconsistent and wasteful action, coordinating activities of multiple actors who may not communicate easily

\footnotetext{
${ }^{3}$ Although it is more typical to separate efficiency and effectiveness, product development efficiency can influence overall organizational effectiveness. Therefore, to maintain a common, unifying focus on new product effectiveness, we place efficiency under the rubric of effectiveness in our mix of dependent variables.
} 
with one another, and assuring that most actions are focused on a single goal. Improvisation offers no particular advantage in this setting. Therefore, in the presence of low environmental change, improvisation will be more disruptive than helpful.

In contrast, rapid environmental turbulence increases the odds that improvisation will provide value. Extensive formal plans in such conditions can have negative consequences because they consume time and resources and provide counterproductive guides to action when the context changes faster than the planning cycle (Eisenhardt and Tabrizi 1995). These circumstances, therefore, actually improve the chances that improvisation will be effective. We propose the following:

$\mathrm{H}_{4}$ : The greater the level of environmental turbulence, the greater the likelihood that improvisation will generate effective (a) products and (b) processes in new product development.

The moderating impact of real-time organizational information flows. Real-time information flows also can facilitate a positive effect for improvisation by playing a powerful coordinating role. One of the crucial functions of plans is to coordinate the action of multiple actors (Galbraith 1973). In the absence of plans, coordination must occur through other mechanisms. Immediate information about the context in which the action is occurring and the actions of other participants enables such coordination (Bastien and Hostager 1988, 1992; Menzel 1981). In theatrical improvisation, for example, actors continually attend to and process instant information on audience reaction to guide their subsequent actions (Spolin 1963). This feedback replaces the coordinating function of a plan because the actors respond to the same audience cues (Huber and McDaniel 1986).

In a product development context, Robins (1991) describes a thriving company that introduces new products at least once a month but has no formal strategic planning. He claims that coordination was achieved because teams have "an insatiable appetite for market intelligence," and each team member "continuously gathers and disseminates anecdotal data from the marketplace" (p. 336). Imai, Nonaka, and Takeuchi (1985, p. 358) also describe product development projects marked by a high degree of experimentation as effective when team members are encouraged "to extract as much information from the marketplace and ... to bounce [ideas] off other members." Following this research, we suggest that real-time information flows can not only bring the "news" that prompts improvisation $\left(\mathrm{H}_{2}\right)$, but also replace the coordinating role of a plan when actors improvise to the same incoming information.

In addition to providing coordination, real-time information flows enable actors to learn the consequences of their actions as they improvise. This immediate information, in turn, enhances the chance that improvisation will be effective because it creates learning about relevant ongoing events (Gioia 1988; Granovetter 1973, 1985). Consistent with this line of reasoning, Eisenhardt and Tabrizi (1995) find that repeated iterations in the product development cycle-which, they argue, provide real-time feedback-are important to the success of the new product outcomes. We predict that

$\mathrm{H}_{5}$ : The greater the level of organizational real-time information flows, the greater the likelihood that improvisation will generate effective (a) products and (b) processes in new product development.

The moderating impact of organizational memory. Although $\mathrm{H}_{3}$ predicts that organizational memory will reduce the incidence of improvisation, there is considerable prior research supporting the idea that a strong organizational memory will enhance the effectiveness of improvisational action. First, much improvisation appears to arise from the recombination of previously successful subroutines of knowledge and action (Borko and Livingston 1989; LeviStrauss 1967; Nonaka 1990). For example, a firm with welldeveloped marketing research competencies and significant consumer insight could recombine existing knowledge and skills to improvise new strategies to respond to unanticipated changes in consumer behavior. In support of this idea, Weick's (1993a) analysis of the Mann Gulch disaster emphasizes that the ability of key members of the fire team to use their existing skills in a novel way was crucial to effective improvisation. Music observers note that musicians with strong preexisting repertoires of melodies, chords, and rhythms and familiarity with other players produce the most powerful improvisations (Berliner 1994). Weick's (1993b, p. 353) characterization of organization design as involving improvisation reflects the importance of memory. He states, "If we think of designers as people who improvise, then the materials they have available to work with are the residue of their past experience and the past experience of people in their design group, the meanings attached to this past experience, observational skills, and their own willingness to rely on imaginative recombination of these materials."

The now-famous account of Honda's introduction of the U.S. Supercub in the United States provides a final example of the importance of organizational memory. Honda's planned introduction of large motorcycles experienced technical difficulties because nontraditional motorcycle customers tried to buy the smaller Supercubs being ridden by Honda's representatives. The Honda team responded to this demand by improvising a new strategy to sell Supercubs through sports stores, in contrast to following their original plan to focus on large motorcycles. Clearly, the effectiveness of this improvisation depended on the Honda team having a rich repertoire of marketing, sales, financial management, and technical routines that could be recombined into an internally consistent strategy that linked successfully to the changing environment (Mintzberg 1996; Mintzberg et al. 1996; Pascale 1996).

Although this argument applies to many forms of innovation, we believe it carries special strength with respect to improvisation. In planned innovation, organizations can gather in advance the tools needed to implement change. They can acquire physical resources, such as machines, as well as advice and ideas from sources outside the organization. The extemporaneous nature of improvisation, however, dictates that there is little or no space between conceiving of and executing an innovation. Thus, the improvisation-ef- 
fectiveness relationship will be even more dependent on existing organizational memory. We predict the following:

$\mathrm{H}_{6}$ : The greater the organizational memory, the greater the likelihood that improvisation will generate effective (a) products and (b) processes in new product development.

\section{Setting}

Data were collected from two midsized firms: FastTrack, a developer of electronic instruments, and SeeFoods, a manufacturer of food products. These companies offer several advantages for testing our hypotheses. First, both companies are well established and have formalized structures but vary in size ( $\$ 2.4$ million and $\$ 2.6$ billion in annual sales, respectively). In addition, both companies have formalized product development processes. Each has detailed steps through which the development process must go and various hurdles to meet before its products move from step to step. For example, SeeFoods has developed its product planning process to the degree that it considers the process a distinct competency and treats it as a trade secret. FastTrack successfully has achieved ISO9000 certification of its product development processes, which indicates some degree of formalization. These properties make the firms good settings for examining improvisation. The firms also provide rich settings for testing our hypotheses because each company takes product development seriously and links it to overall organizational success. They therefore engage in various product development activities, which provided us with many opportunities to observe the development process.

The two firms do contrast on two dimensions, therefore providing some variation in our study conditions. First, one is a consumer packaged-goods firm, and the other a technology-oriented industrial firm. Second, in one firm we studied, the project was in the concept and prototype development stages, whereas in the other firm, the project was in the market development and product introduction stages of the new product development process. Both aspects of differentiation improve the generalizability of our results. In both firms, employees understood we were conducting a study of product development, but no mention was made of improvisation to avoid demand effects about its incidence or impact. In each firm, we focused on one development project, which was selected because it was representative of other projects in each firm. The teams working on these projects both were cross-functional, with ten active members at SeeFoods and seven at FastTrack.

\section{Data Collection Procedures}

Investigators attended, recorded, and transcribed the meetings of the product development teams during a nine-month period. Meetings generally were held once a week. However, holidays, vacations, and schedule conflicts meant some meetings were missed, which resulted in approximately 25-30 meetings attended in each of the firms. To generate fine-grained but systematic data at the level of specific team actions, we identified action events from these meetings and asked key informants to evaluate them in terms of a wide va- riety of variables, including activities that occurred prior to or at the same time as the event and outcomes associated with the action event.

Determining the scope and nature of these action events was, therefore, an important part of the research effort. New product development projects are composed of a series of ongoing activities that are, in some sense, seamless. Therefore, to understand and evaluate improvisation, we had to both appreciate this larger unfolding of activities and decide how to divide it into a series of events that could be evaluated and judged independently.

Action events are defined as discrete activities undertaken by a new product development unit. Following from our conceptualization, we restricted our sample to organizational-level actions, defined as those undertaken by the new product team. Therefore, actions taken outside of the group or without the group's approval were not considered organizational for our purposes. An action event could involve a team engaging in any of the following activities: making changes to a new product, calling a supplier to change the size of a part, making a decision to use a new distributor, releasing test procedures, finding product problems, preparing documents for regulation filing, doing a store walk, creating concept boards, making targeting decisions, generating brand names, deciding to delay a project, engaging in a focus group briefing, or participating in a focus group or a creativity session. One additional condition was placed on the action identification process: The action had to have some possibility (even remote) of influencing new product outcomes. This condition did not bias our sample toward actions that were likely to influence outcomes. Instead, it eliminated minor activities of the team, such as decisions about when and where to meet and other conversation that was related to social activities among team members and not the product.

To ensure that our identification of the actions was complete and unbiased, we used several safeguards. First, four transcripts were selected randomly from each site, and action events were coded independently by two investigators familiar with the site. This approach yielded high interjudge reliability (92\% agreement). Second, product development team meetings evolved as primary data sources from which we derived action events because they represented a consistent vehicle that brought all the project members together and because the meetings were the primary means by which members exchanged information about actions that influenced the project. To reduce the possible bias in team meetings, project teams were asked on three different occasions to list all the things they had done on behalf of a project during the preceding week. These lists were compared with meeting transcripts, and coverage was adequate ( $90 \%$ coverage).

Each of the team meetings we observed could potentially produce dozens of actions, making their evaluation by respondents difficult and burdensome. Therefore, to reduce the set of actions that would constitute our sample, we randomly selected 2 organizational actions from those coded in 
a given meeting. ${ }^{4}$ This resulted in the selection of 107 action events for our sample. When an action event was selected for informant evaluation, we set in motion a series of data collection events. To begin, informants completed an action assessment form, within a week of the action occurring, that asked them to rate the action and various environmental and organizational activities that occurred prior to and during the time the action was unfolding. This included an informant rating of organizational improvisation, memory, and real-time information flows and an assessment of the level of environmental turbulence associated with the action event. After approximately four weeks, the same informants evaluated the short-term impact of each action event in terms of product and process outcomes. The key informants in completing both forms were the team leaders because they were in attendance at every meeting, were aware of team actions, and had a broad view of the project.

\section{Measures}

In this section, we report the properties of our measures, approximately half of which were multi-item and half singleitem measures. Multi-item measures were a mix of formative and reflective indicators. This mix was adopted to safeguard against the hazards of key informant burnout. Each of our key informants completed approximately 100

\footnotetext{
4 Our initial goal was to sample systematically high and low improvisation actions to ensure that our sample would contain variance. However, after attempting to do this for several weeks, we abandoned the approach for two reasons. First, from our observations of team meetings and interviews with key informants, it seemed that much of what occurred during meetings was, at least in part, an improvisation. Therefore, variance would be easier than we had expected to capture. Second, we determined it was more appropriate for our informants to assess the degree to which they improvised than for us to make such judgments without a clear understanding, a priori, of how much or how little planning had preceded an action. This realization shifted our design, and we allowed informants to rate the degree of improvisation in an action following its enactment.
}

questionnaires: 50 action assessments immediately following the action and 50 short-term impact forms four weeks after the action. Therefore, they completed two questionnaires each week for the study. Given this workload, we tried to make each questionnaire no more than a page long. This meant sacrificing some depth on individual measures. We focused our efforts on developing multi-item measures for those constructs that were considered a priori difficult to measure, such as improvisation.

Because the composition of formative measures is driven by conceptual criteria-which is coverage of the construct domain-and not by predictions of correlation between items in that space, formative measures were not subject to reliability or factor analytic approaches (Bagozzi 1994). The remaining reflective measures were examined for unidimensionality and reliability. In Table 2 , we present an overview of the psychometrics associated with each measure.

Appendix B contains a complete listing of all the measures used in this study. The organizational improvisation level of each action event was evaluated on the action assessment form and was measured on three semantic differential seven-point scales with the following anchors: (1) figured out action as we went along/action followed a strict plan as it was taken, (2) improvised in carrying out this action/strictly followed our plan in carrying out this action, and (3) ad-libbed action/not an ad-libbed action. The mean improvisation level is $M=4.252$ (s.d. $=1.985$ ) and the coefficient alpha exceeded acceptable standards $(\alpha=.79)$.

Because of the centrality of improvisation to our work, two additional safeguards were taken to measure it. First, it was rated by two investigators involved in the site, and there was $70 \%$ agreement regarding whether improvisation was low (1), moderate (4), or high (7). The mean investigator rating $(M=4.014$, s.d. $=1.539)$ also compared well with the mean informant rating. Second, because we claim that improvisation is distinct from innovation, we examined the discriminant validity of the level of improvisation and the

TABLE 2

Measurement Information

\begin{tabular}{|c|c|c|c|c|c|c|c|c|c|c|c|c|}
\hline & Mean & $\begin{array}{l}\text { Standard } \\
\text { Deviation }\end{array}$ & (1) & (2) & (3) & (4) & (5) & (6) & (7) & (8) & (9) & (10) \\
\hline (1) Organizational improvisation & 4.25 & 1.98 & .83 & & & & & & & & & \\
\hline $\begin{array}{l}\text { (2) Environmental turbulence } \\
\text { (3) Organizational real-time }\end{array}$ & 2.12 & 1.22 & .18 & $-a$ & & & & & & & & \\
\hline information flows & 5.86 & 1.85 & .03 & -.14 & $\rightarrow b$ & & & & & & & \\
\hline (4) Organizational memory & 4.36 & 1.78 & -.60 & -.07 & .04 & .84 & & & & & & \\
\hline (5) Design effectiveness & 5.03 & 1.06 & -.08 & -.23 & .30 & .07 & -a & & & & & \\
\hline (6) Market effectiveness & 4.87 & .81 & -.22 & -.12 & .30 & .29 & .65 & .70 & & & & \\
\hline (7) Cost efficiency & 4.05 & .76 & -.08 & -.20 & .06 & .08 & .19 & .11 & -b & & & \\
\hline (8) Time efficiency & 4.08 & .89 & .01 & -.14 & .20 & .03 & .05 & .03 & .35 & .89 & & \\
\hline (9) Team functioning & 4.61 & .80 & -.34 & -.12 & .20 & .17 & .43 & .60 & .11 & .16 & .86 & \\
\hline (10) Team learning & 5.12 & .93 & -.30 & -.24 & .29 & .25 & .53 & .64 & .17 & .13 & .60 & .73 \\
\hline
\end{tabular}

aFormative scale, therefore alpha is not reported.

bSingle-item measure, therefore no alpha or correlation is reported.

Notes: The coefficient alpha for each measure is on the diagonal and the intercorrelations among the measures are on the off-diagonal. Correlation coefficients greater than .20 are significant, $p<.05$. 
level of innovation of the focal action. Informants rated innovation and improvisation on the same form. Innovativeness was measured by asking key informants to rate the level of innovation on a two-item semantic differential scale with (1) innovative action/ordinary action and (2) novel action/standard action as the anchors. The two innovativeness items correlated well $(\rho=.70)$.

The test of discriminant validity between innovation and improvisation required constraining and freeing the phi coefficient between the two measures using LISREL 8 . The model with the free coefficient was found to be superior to the fixed coefficient $\left(\Delta \chi^{2}(1)=5.31\right)$, exceeding the standard necessary to show discriminant validity $\left(\Delta \chi^{2}{ }_{(1)}=3.84\right)$. Therefore, innovation and improvisation are empirically distinct. ${ }^{5}$

The three explanatory variables were measured on seven-point Likert scales in which the anchors depended on the variable. The degree of environmental turbulence occurring around the action event was measured using a three-item, formative measure, where 1 was "none" and 7 was "a lot" for the following items: When the action was taken, how would you rate the level of change [defined as any deviation from the status quo] within (1) your team, (2) your firm, and (3) external sources [customers, suppliers, distributors]. The mean level of external change was $2.136($ s.d. $=1.243)$. Because the measure is a formative indicator, rather than reflective, we do not report a reliability coefficient.

Informants also evaluated the level of real-time organizational information flows that occurred using a single-item measure that asked for a rating of the level of face-to-face, telephone, or e-mail information transferred among team members just before the focal action $(\mathrm{M}=4.078$, s.d. $=$ 1.058), using the same anchors.

Organizational memory level was measured by asking informants to evaluate the memory level regarding an action using a four-item scale adapted from our previous (1997) study. Informants were asked to rate the extent of their agreement with the following items: For this action, my team has (1) well-defined procedures, (2) a standard approach, (3) a great deal of knowledge, and (4) strong skills. The measure had a mean of 4.392 (s.d. $=1.784)$ and adequate reliability $(\alpha=.79)$.

Of all the independent variables, organizational improvisation and memory are the only measures that are multiitem and reflective in nature. Therefore, we examined the discriminant validity of organizational memory and improvisation. As previously, the test of discriminant validity involved constraining and freeing the phi coefficient between the two measures using LISREL 8 . The model with the free coefficient again was found to be far superi-

5 We ideally would have performed discriminant validity checks between all the variables from which we previously conceptually distinguished improvisation (including adaptation, learning, and opportunism). However, because of the severe constraints imposed on our informants, we chose to focus our empirical efforts on innovation. We believe it is closest conceptually to improvisation and, therefore, perhaps the competing variable most crucial to our perspective. or to the fixed coefficient $\left(\Delta \chi^{2}(1)=52.00\right)$, which indicated discriminant validity between organizational memory and improvisation

Dependent variables. These variables were assessed by our informants four weeks after the action event occurred Informants were given a one-page survey with the action event described in detail at the top of the page. In addition, because of the time lag, a portion of the transcript relevant to the action generally was attached to the page to jar the informant's memory of the event. Informants did not have access to their original evaluations of the event or their ratings of the informational actions occurring around it. All dependent variables were evaluated on a seven-point scale, where 7 was a positive and 1 was a negative effect of the action on the particular outcome. Informants were asked to rate how, "on balance," the action event has or is likely to have influenced each dependent variable. They appeared to have no problems in making such assessments.

Following our conceptualization, two product-effectiveness dependent measures were used in this research. Design effectiveness was measured with a two-item formative scale that assessed the impact of the action on the performance and design of the product. The two items have an acceptable correlation $(\rho=.48)$. Influenced by Griffin and Page's $(1993,1996)$ work, we measured market effectiveness with a three-item scale that described the impact of the action on the sales, customer acceptance, and success of the new product. The items have an alpha of .70 .

Four process effectiveness dependent variables also were evaluated. Cost efficiency was measured by a singleitem measure of the estimated cost structure of the new product (Griffin and Page 1993, 1996). Time efficiency was measured by a three-item measure that asked respondents to rate the (1) length of the product development process, (2) speed of the product development process, and (3) project timeliness. These items are reliable $(\alpha=.89)$.

Team functioning refers to the impact of the action event on the degree to which the team works well together. This was evaluated using a three-item measure that asked informants to assess the impact of the action on (1) team commitment level, (2) team functioning, and (3) team enthusiasm. These items are reliable $(\alpha=.86)$. Finally, team learning was measured by asking informants to assess the impact of the action on (1) the way the team thinks about the project, (2) the team's certainty level, (3) the team's understanding level, and (4) how much the team learned. These four items are reliable $(\alpha=.73)$.

Three of the process effectiveness outcomes (time efficiency, team functioning, and team learning) are multi-item and reflective in nature. Therefore, measure development required examining their discriminant validity. As we did previously, we established a base model that did not reflect the correlation between measures. Then we examined how model fit changed when we constrained the phi coefficient between different pairs of the three measures to equal one. Results indicate that the model with the free phi coefficient was a better fit in all three cases, which indicated discriminant validity in time efficiency and team learning $\left(\Delta \chi^{2}(1)=\right.$ 16.53), time efficiency and team functioning $\left(\Delta \chi^{2}(1)=\right.$ 
28.17), and team learning and team functioning $\left(\Delta \chi^{2}(1)=\right.$ 8.78).

\section{Model-Testing Approaches}

We used three distinct model testing approaches to examine the proposed hypotheses. First, we used simple descriptive statistics to examine the existence of improvisation in the new product actions we sampled. Second, we used a multivariate linear regression model to examine the impact of environmental turbulence, organizational real-time information flows, and organizational memory on the incidence of improvisation in new product actions. Third, we performed a split group analysis (Arnold 1982; Cohen and Cohen 1983) to examine the impact of the three moderators-environmental turbulence, organizational real-time information flows, and organizational memory-on the organizational improvisation-effectiveness relationships. This approach involved creating high and low levels of each moderator variable by performing a median split. We then examined the relationship between improvisation and the various outcomes in the high and low moderator variable conditions and compared the regression results from these two conditions using a t-test, to determine if the regression coefficients were different across the two moderator conditions (Pedhazur 1982). If the t-test of differences in the beta coefficients was significant, we had found evidence of moderation and inspected the direction of moderation. We chose this approach over moderator regression analysis (MRA) because MRA demands that all main and interaction effects associated with the proposed moderating influences be entered into the model (Pedhazur 1982). ${ }^{6}$ In this study, MRA would have involved seven predictors (i.e., improvisation, memory, real-time information, environmental turbulence, improvisation $\times$ memory, improvisation $\times$ real-time information, and improvisation $\times$ environmental turbulence). Using MRA with the number of variables and the sample size of this study likely would have resulted in underpowered tests of the hypotheses.

\section{Results \\ The Incidence of Improvisation}

Simple descriptive statistics suggest that organizational improvisation occurred in our sample of new product actions. The mean level of improvisation, as rated by informants, was 4.252 on a seven-point Likert scale (s.d. = 1.985), where 7 represents greater improvisation. The scale exhibited considerable range, running from 1 to 7 with a mode of 5 and a median of 4.667. The distribution is fairly even across all levels of improvisation but is skewed slightly toward higher levels of improvisation. For example, if we defined as "primarily improvisational" those actions that were rated higher than five, $47.5 \%$ of the actions would qualify; if we used a cutoff of higher than six, $24.1 \%$ would quali-

${ }^{6}$ Despite differences at the multivariate level, a univariate MRA test is identical in structure to the split-group analysis used here (for related proofs, see Arnold 1982; Cohen and Cohen 1983). fy. The central tendency then was toward improvisation. However, with a standard deviation of 1.98 , there was also quite a bit of variance in improvised behavior. In Table 3, Part A, we depict the frequency distribution of improvisation in our sample.

\section{Factors Influencing the Incidence of Improvisation}

Considering the factors that could influence the incidence of improvisation, we tested the first three hypotheses in a single multivariate regression model. The results, which appear in Table 3, Part B, suggest that the overall model is significant (Adjusted $\mathrm{R}^{2}=.39, \mathrm{~F}_{(3,88)}=20.97, p<.001$ ). Results also indicate that environmental turbulence is a marginally significant, positive predictor of the level of improvisation in new product actions $(b=.252, t=1.88$, $p<.10$, two-tailed test), in support of $\mathrm{H}_{1}$. Organizational real-time information flows do not have a significant impact on the incidence of organizational improvisation $(b=$ $.100, \mathrm{t}=1.14, p>.10$ ), thus failing to support $\mathrm{H}_{2}$. Finally, organizational memory has a negative effect on the level of improvisation $(b=-.687, t=-7.520, p<.001)$, in support of $\mathrm{H}_{3}$.

\section{Factors Influencing the Effectiveness of Improvisation}

The split group analyses results appear in Table 3, Part C. We note there that high levels of environmental turbulence have a positive influence on improvisation's impact on design effectiveness $\left(\mathrm{t}_{(86)}=2.83, p<.05\right)$. We find that when environmental turbulence is low, improvisation has a negative effect on design effectiveness, but in the presence of high environmental turbulence, improvisation improves design effectiveness. Environmental turbulence does not have, however, a statistically significant moderating impact on market effectiveness $\left(t_{(86)}=1.21, p>.10\right)$. These results thereby support $\mathrm{H}_{4 \mathrm{a}}$ with respect to technical design and quality outcomes but not in terms of the product's effectiveness using market indicators.

Environmental turbulence has equally mixed effects on the improvisation-process outcome relationships. Turbulence improves the extent to which the team reports it learned $\left(\mathrm{t}_{(86)}=3.42, p<.05\right)$ and functioned smoothly $\left(\mathrm{t}_{(86)}=1.98, p<.05\right)$ while taking improvisational actions, in support of $\mathrm{H}_{4 b}$. However, the improvisation-cost efficiency relationship becomes weaker and more negative when turbulence is high, and the improvisation-time efficiency relationship is not influenced at all, thus failing to support $\mathrm{H}_{4 \mathrm{~b}}$. These results suggest important trade-offs for the use of improvisation in conditions of environmental turbulence.

Organizational real-time information flows have a more uniform positive influence on the extent to which improvised new product actions influence design $\left(\mathrm{t}_{(94)}=6.21, p<\right.$ $.05)$ and market $\left(\mathrm{t}_{(94)}=4.76, p<.05\right)$ effectiveness, in support of $\mathrm{H}_{5 \mathrm{a}}$. However, real-time information flows do not have the same positive influence on process outcomes, thus failing to support $\mathrm{H}_{5 \mathrm{~b}}$. Improvised new product actions do not have a greater impact on cost efficiency $\left(\mathrm{t}_{(94)}=.66, p>\right.$ 
TABLE 3

Tests of Hypothesized Relationships

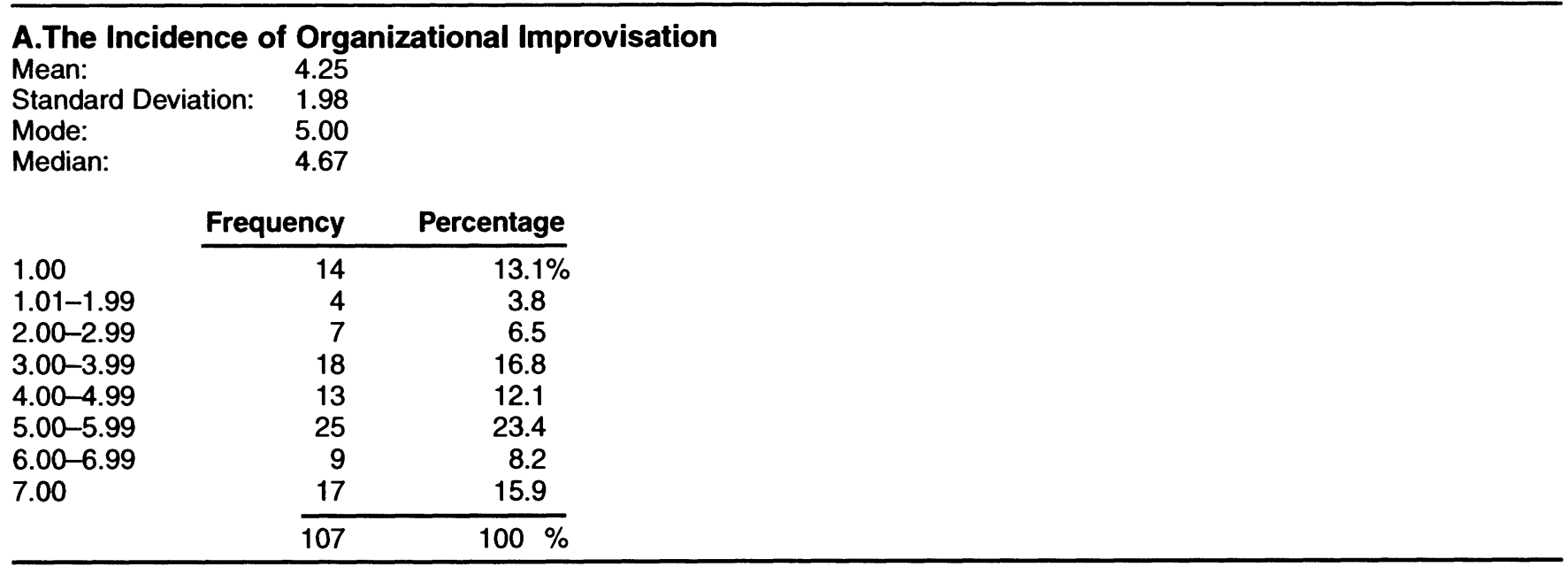

B. Factors Influencing the Incidence of Organizational Improvisation

Overall model, $\mathrm{F}_{(3,88)}=20.97, p<.001$, Adjusted $\mathrm{R}^{2}=.39$

Independent Variables

\begin{tabular}{|c|c|c|c|c|c|c|}
\hline \multirow[b]{2}{*}{ Dependent Variable } & \multicolumn{2}{|c|}{$\begin{array}{l}\text { Environmental } \\
\text { Turbulence Level }\end{array}$} & \multicolumn{2}{|c|}{$\begin{array}{l}\text { Real-Time Information } \\
\text { Flow Level }\end{array}$} & \multicolumn{2}{|c|}{$\begin{array}{l}\text { Organizational } \\
\text { Memory Level }\end{array}$} \\
\hline & b & t-value & b & t-value & b & t-value \\
\hline Improvisation & .252 & $\left(1.88^{\star \star}\right)$ & .100 & (1.14) & -.687 & $\left(-7.52^{\star}\right)$ \\
\hline
\end{tabular}

C. Factors Influencing the Effectiveness of Organizational Improvisation

\begin{tabular}{|c|c|c|c|c|c|c|c|c|c|}
\hline \multirow[b]{4}{*}{ Dependent Variables } & \multicolumn{9}{|c|}{ Moderating Variables } \\
\hline & \multirow{2}{*}{\multicolumn{3}{|c|}{$\begin{array}{l}\text { Environmental } \\
\text { Turbulence Level } \\
\qquad(n=86)\end{array}$}} & \multirow{2}{*}{\multicolumn{3}{|c|}{$\begin{array}{l}\text { Real-Time Information } \\
\text { Flow Level } \\
(n=95)\end{array}$}} & \multirow{2}{*}{\multicolumn{3}{|c|}{$\begin{array}{l}\text { Organizational } \\
\text { Memory Level } \\
\qquad(n=94)\end{array}$}} \\
\hline & & & & & & & & & \\
\hline & Lowa & High & t-value & Low & High & t-value & Low & High & t-value \\
\hline $\begin{array}{l}\text { Product effectiveness } \\
\text { Design effectiveness } \\
\text { Market effectiveness }\end{array}$ & $\begin{array}{l}-.17 \\
-.27\end{array}$ & $\begin{array}{r}.17 \\
-.16\end{array}$ & $\begin{array}{l}2.83^{\star} \\
1.21\end{array}$ & $\begin{array}{l}-.57 \\
-.54\end{array}$ & $\begin{array}{l}-.01 \\
-.18\end{array}$ & $\begin{array}{l}6.21^{\star} \\
4.76^{\star}\end{array}$ & $\begin{array}{l}-.13 \\
-.13\end{array}$ & $\begin{array}{r}.08 \\
-.06\end{array}$ & $\begin{array}{c}1.65^{\star \star} \\
.64\end{array}$ \\
\hline $\begin{array}{l}\text { Process effectiveness } \\
\text { Cost efficiency } \\
\text { Time efficiency } \\
\text { Team functioning } \\
\text { Team learning }\end{array}$ & $\begin{array}{r}.02 \\
.07 \\
-.36 \\
-.35\end{array}$ & $\begin{array}{r}-.22 \\
.09 \\
-.20 \\
.00\end{array}$ & $\begin{array}{l}-2.91^{\star} \\
.16 \\
1.98^{\star} \\
3.42^{\star}\end{array}$ & $\begin{array}{r}-.14 \\
.09 \\
-.40 \\
-.59\end{array}$ & $\begin{array}{r}.09 \\
.02 \\
-.39 \\
-.28\end{array}$ & $\begin{array}{r}.66 \\
-1.46 \\
.10 \\
3.81^{\star}\end{array}$ & $\begin{array}{l}-.18 \\
-.18 \\
-.41 \\
-.32\end{array}$ & $\begin{array}{r}.09 \\
.17 \\
-.23 \\
-.11\end{array}$ & $\begin{array}{l}2.83^{\star} \\
3.15^{\star} \\
1.98^{\star} \\
1.98^{\star}\end{array}$ \\
\hline
\end{tabular}

aNumbers in the low and high columns represent the standardized beta coefficient (b) for the impact of improvisation on each dependent variable under low and high moderating conditions.

${ }^{\star} p<.05$.

${ }^{* \star} p<.10$.

$.10)$, time efficiency $\left(\mathrm{t}_{(94)}=-1.46, p>.10\right)$, or team functioning $\left(\mathrm{t}_{(94)}=.10, \mathrm{p}>.10\right)$ when real-time information flows are high rather than low (see Table 3 , Part C). Only the impact of improvisation on team learning improves when real-time information flows are high $\left(\mathrm{t}_{(94)}=3.81, p<.05\right)$.

Finally, $\mathrm{H}_{6}$ predicts that high levels of organizational memory will increase the likelihood that improvisation will generate effective products and processes in new product development. The results indicate that organizational memory uniformly improves the impact of improvisation on var- ious process outcomes, including cost efficiency $\left(\mathrm{t}_{(94)}=\right.$ $2.83, p<.05)$, time efficiency $\left(\mathrm{t}_{(94)}=1.98, p<.05\right)$, team functioning $\left(\mathrm{t}_{(94)}=3.15, p<.05\right)$, and team learning $\left(\mathrm{t}_{(94)}=\right.$ $1.98, p<.05)$. These results support $\mathrm{H}_{6 \mathrm{~b}}$. Likewise, organizational memory marginally improves the extent to which improvised new product actions result in design effectiveness $\left(\mathrm{t}_{(94)}=1.65, p<.10\right)$. However, memory does not improve the likelihood that improvised new product actions will result in market effectiveness $\left(\mathrm{t}_{(94)}=.64, p>.10\right)$, thus providing mixed support for $\mathrm{H}_{6 \mathrm{a}}$. 


\section{Discussion and Implications}

Our conceptual work builds on prior interdisciplinary research and suggests that improvisation can play a role in the new product development process. An investigation of marketing literature provides few positive empirical accounts of extemporaneous action in managerial action, suggesting instead that more fruitful action is planned and then executed. In an attempt to address this gap in the literature, we have documented the incidence of improvisation and the factors that influence that incidence. Drawing on equivocalities in literature, we further suggest that improvisation is understood best as perhaps having both positive and negative outcomes for firms. This mixed assessment draws us to try to understand the conditions in which improvisation might be deployed effectively by organizations. We propose and test several such conditions.

In this section, we address the theoretical and practical potential of our view of improvisation in several ways. First, we discuss the limitations of our work. Second, we review the pattern of our results in more detail and with an eye toward understanding the conditions in which the moderators (1) change improvisation's effect from negative to positive or (2) reduce the negative impact of improvisation. Third, we discuss several trade-offs in managing the incidence and effectiveness of improvisation in organizations and highlight the implications of these trade-offs.

\section{Limitations}

Our research has several limitations. First, despite the longitudinal approach we adopted, the use of two firms limits the generalizability of our results. Similar to Hutt, Reingen, and Ronchetto (1988), we initially sought to control for many of the firm factors that might influence either the rate of improvisation or its impact by limiting ourselves to two firms. Furthermore, the challenges of longitudinal access to organizations, especially to proprietary activities such as new product development processes, made our method choice more reasonable. This is particularly true given that we selected actions from among those that occurred during weekly product development meetings, all of which were attended, recorded, and transcribed. Other approaches that may be more externally valid might have created other problems in generating an unbiased sample of actions. Therefore, our approach offers solid, internally valid evidence of improvisation that further research might examine in more firms using a less sensitive methodology.

Second, our hypotheses focus on three information factors that have been discussed in prior literature on improvisation and that deserve empirical attention. Although still limited, these factors include the effect of different information sources (internal and external) and types (stocks and flows) on improvisation. Further research could involve considering a more comprehensive study of improvisation that extends the connections between information and improvisation presented here. This approach could develop a more general framework of the antecedents and consequences of improvisation in new product development, using relevant industry, firm, product, environmental, and individual team factors. Many of the factors examined by Hutt, Reingen, and Ronchetto (1988) would be fruitful av- enues for such a framework. For example, the role of culture, structure, boundary spanners, and product champions as catalysts for and facilitators of improvisation would be appropriate factors. Additional research also could involve examining the role of individual improvisation in organizational improvisation, a factor we did not investigate.

Third, though this research involved examining the impact of improvisation on short-term new product effectiveness, it also would be valuable to examine the impact of improvisation on long-term organizational outcomes. Our research also was limited to new product development actions. However, many other marketing contexts are also relevant contexts for the study of improvisation. Advertising and personal selling stand out as areas in which we would expect improvisation to occur at even higher levels. Additional research could examine the incidence of improvisation and attempt to demonstrate the generalizability of our findings across multiple contexts.

Finally, further research could address the possibility of common methods variance influencing our results, because the same informants rated aspects of both actions and outcomes. However, because observers independently identified the action, the ratings of actions and outcomes were accomplished at significantly different times, and informants had no record of prior ratings when performing their outcome ratings, the chance of informant preconceptions producing the results here is reduced. Further research could use multiple measures of actions and outcomes to ensure even further the lack of common methods or informant bias.

\section{Pattern of Improvisation Results}

Considerable research on organizations suggests that formalized organizations with well-developed product development procedures are relatively unlikely to engage in improvisation (Scott 1987). Contrary to that research, our first basic finding is that, even in two well-established organizations with formal structures, roles, and procedures, improvisation occurs with substantial regularity in the product development process.

Prior research also has tended to highlight either the dangers of improvisation or its potential for helping firms adapt. Our pattern of results supports a more contingent view of improvisation. For example, we provide some support for the traditional concern regarding the risks of improvisation because, in five of the specific outcome variables we observed, our moderating variables had a positive effect but worked by reducing the negative effect of improvisation. Thus, though the moderating conditions enhanced the value of improvisation, as we had expected, the conditions were not strong enough to make the net effect of improvisation positive.

In other cases, however, the moderating conditions reversed the negative impact of improvisation. For example, in conditions with low organizational memory, improvisation had a negative effect on design effectiveness, cost efficiency, and time efficiency. However, in the presence of high organizational memory, improvisation had a positive effect on these outcomes. These findings support the general argument that emergent processes might have value in uncertain or ambiguous conditions (Burgelman 1983; Miner

\section{4 / Journal of Marketing, July 1998}


1987). They also support the more recent arguments of scholars who claim that improvisation represents an important competency that can produce value for organizations in certain conditions (Eisenhardt and Tabrizi 1995; Moorman and Miner 1998; Weick 1987).

\section{Trade-Offs in Improvisation}

A common theme that runs through our conceptual framework and results is that improvisation, similar to most strategic actions, involves trade-offs and potential synergies for marketing organizations. This theme is evidenced in several ways.

Recall that our findings show that memory reduces the likelihood of improvisation, but it also increases the effectiveness of improvisation when improvisation does occur. Therefore, the same organizational feature that makes improvisation effective is likely to reduce the chances of its occurrence. Too powerful a memory, then, can remove improvisation from the organization's repertoire, whereas too little memory can render the improvisation that occurs ineffective. This result suggests that there is a threshold of memory level at which improvisation is a valuable organizational activity, with levels below or above this threshold reducing the chances of such an impact. This trade-off implies that organizations must minimize the fixating aspects of memory when improvisation is needed and evoke memory as improvisation is unfolding if it is to be effective. This delicate balance of restraining and infusing memory at certain times requires a greater understanding of memory, its forms, and the degree to which these forms restrict extemporaneous actions in organizations. For example, in a forthcoming article (1998), we distinguish between the effects of declarative organizational memory (facts and theories) on the novelty of organizational outcomes versus the effects of procedural organizational memory (skills and routines) on the timeliness of organizational outcomes.

Another trade-off associated with memory that is evident in our results is that organizational memory facilitates the impact of improvisation on all new product and process outcomes, except those associated with external market effectiveness. Although this is consistent with research that suggests an internal firm focus should reduce market success (Day and Nedungadi 1994; Deshpandé, Farley, and Webster 1993), none of our memory measures involve skills and knowledge regarding how a new product activity fits with customer needs and wants. Therefore, the value of memory appears to be linked tightly to its measured content.

Real-time information flows moving through organizations present a different set of trade-offs for firms. Real-time flows were found to increase the extent to which improvisation produces effective new products but to reduce the positive effect of improvisation on process outcomes (excluding learning). Improvisations were less cost and time efficient, and groups engaging in them appeared to function less effectively when the level of real-time information transfer was high. Despite the inefficiencies associated with real-time information flows, improvisation continued to promote design and market effectiveness when real-time flows were high. Therefore, similar to our prior discussion of memory, our results appear to recommend a restricted zone of real-time information flow in which sufficient amounts of real-time information are needed to promote a positive relationship between improvisation and product effectiveness. However, flows cannot be so high as to create negative improvisation-process effectiveness relationships, which, over time, might undermine product effectiveness levels.

Finally, as with the other informational moderators, the influx of information about environmental change brings with it certain trade-offs. In particular, our results suggest that high levels of information about environmental changes during improvisation result in increased product design effectiveness. Across all of the informational moderators, product design effectiveness has the most to gain from highly improvisational actions when levels of information are high. However, consistent with the other results, firms have to accept that the influx of the high levels of environmental change information might have corresponding risks, particularly higher costs. Such trade-offs also appear in other research on new products (Griffin and Page 1993; Moorman 1995).

In summary, these results suggest that improvisation is a strategy of emergent learning (Mintzberg 1996) that can be employed as a substitute for planning (Weick 1987). However, our results clearly suggest that improvisation is not necessarily a free good, nor is it one that translates into effective outcomes in all conditions. On the contrary, our results consistently emphasize that improvisation must be directed explicitly, its trade-offs and tensions acknowledged and managed, and the conditions in which it is effective understood and nurtured by organizations.

\section{Future Research Issues}

There are many issues that our initial inquiry into improvisation did not consider. We discuss several here as a way of establishing a strategy for additional research on this topic. Regarding improvisation generally, we recommend that further research consider whether improvisation is driven by firm mismanagement, environmental change, or the decision to use improvisation purposively as part of firm strategy. In the domain of product development, we encourage investigation of improvisation's occurrence and impact in different (1) project phases, (2) product categories, and (3) industries. Whether a product development project represents an incremental or a radical change from a prior product is an especially important contingent worthy of further research. The risks for improvisation intuitively seem higher in radical product development projects because of the probable lack of relevant organizational memory to inform the product development process. At the same time, improvisation may be more likely to occur in radical product development projects that lack memory. Teasing out these and other possibilities is an important next step.

Another topic we did not address is the nature of the group or individual factors that spawn improvisation during the new product development process. The research tradition on product championing includes projects that are initiated outside the formal new product development process (Burgelman 1983; Hutt, Reingen, and Ronchetto 1988). It would be interesting to consider what motivates these infor- 
mal improvisation efforts. What form does improvisation take when the focus is on a major strategic decision that involves multiple stakeholders across business units? The focus of the present study is restricted to improvisation in the narrow confines of a structured development process.

Our focus was the impact of improvisational activities on the project in which they occurred. However, it is possible that improvisations have long-term impacts as well. Team members sometimes observed that a particular improvisational action not only worked in the current project but also could be used in other settings or future projects. Our quantitative results support such an impact and suggest that improvisation positively affected team learning outcomes in high information conditions. Additional research could fruitfully investigate whether improvisation serves as a systematic form of unplanned experimentation in organizations. If this function is confirmed, the potential "second-order" impact creates an additional factor in the calculus of improvisation's value to organizations. Each improvisation might have, on average, a low expected value as a possible new routine for the organization. But on rare occasions, an improvisational act (or "local experiment") might represent a real improvement over prior practices and thus be a very useful experiment (Miner, Moorman, and Bassoff 1997).

Finally, our qualitative observations lead us to suspect that, in addition to building a baseline model of factors that can move improvisation from a hindrance to a potential advantage, contemporary researchers should entertain the possibility that the boundary conditions for organizational improvisation might be changing. Corporate intranets, computer-aided design, and manufacturing and point-of-sale data can change the temporal links between actions in ways that previously were not possible. In many ways, this change enhances the potential for accurate planning; however, it also might enhance the possibility of fusing planning and acting. Therefore, it appears that improvisation's boundary conditions are changing even as we begin to examine the phenomenon in a systematic way.

\section{Conclusion}

This article examines the incidence and effectiveness of improvisation during the new product development process. Hypotheses were developed examining the impact of various types and sources of information on the level and effectiveness of improvisation. We find that improvisation is prevalent and occurs when organizational memory is low but environmental turbulence is high. Our results support traditional concerns that improvisation can reduce new product effectiveness but also indicate that informational factors emanating from the environment and organization can reduce these negative effects or even create a positive effect of improvisation on new product outcomes.

These results suggest that there are conditions in which improvisation might be not only what organizations do practice but also what they should practice to flourish. We suggest that these conditions involve the careful deployment and management of other organizational resources, such as memory, real-time information flows, and the in- flux of information about environmental turbulence, so as to promote effective new product development outcomes when improvisation occurs. The management of such resources requires attention to the trade-offs and synergies between improvisation, organizational factors, and the environmental context.

\section{Appendix A}

\section{An Example of Organizational Improvisation}

To make concrete the distinction between improvisational and nonimprovisational activities, consider the contrast between two product development processes in a single organization. For Product A, the organization follows its typical product development procedure. The marketing department analyzes market potential, pricing questions, and details of customer demand for a new instrument that is based on an emerging technology. The engineering department analyzes technical problems with prior products, the feasibility of meeting quality specifications at certain price levels, the availability of key components at particular prices, and the time needed to produce the new product. On the basis of these analyses, the senior officers approve a plan, budget, and timeline for this product's development, manufacturing, and launch. A product team is appointed to implement detailed design and prototyping activities. After being checked, final manufacturing specifications and procedures are approved and trigger implementation of the manufacturing process and product introduction.

Product B follows a different path. A customer of one of the firm's current scientific testing instruments complains to members of the original design-and-support team that he needs an instrument to assess certain features of selected opaque liquids, instead of those of the clear liquids for which the instrument was designed. Team members meet and think of a recent scientific advance that may make it possible to investigate necessary materials. Using time between other projects to which they officially were assigned, two team members pull together a new product in three months that uses parts from old products and a few new parts they had ordered. They build the new machine themselves as they progress. At the end of the processes, they sell the custom-designed machine to the customer.

In Product A, planning formally preceded implementation in both design and manufacturing activities. Details of both product features (price, performance specifications, components, and potential sources for them) and the product development process (team members, responsibilities, checkpoints, and intermediate target dates) were specified before they were implemented. Manufacturing plans, specified in advance, detailed aspects of production outcomes and procedures. Clearly, Product B represented a more improvisational activity. A broad goal, but little product or manufacturing planning, preceded development. Final technical performance levels, exact components, size, shape, and actual assembly all unfolded as the team progressed. Although small improvisations to solve unexpected design problems arose during development of Product A, a dramatically greater proportion of both the product and manufac- 
turing design occurred directly during their implementation for Product B, indicating improvisation.

\section{Appendix B}

\section{Measures}

Organizational Improvisation

New Measure

Seven-point semantic differential scale.

Rate the action:

-Figured out action as we went along/Action followed a strict plan as it was taken.

-Improvised in carrying out this action/Strictly followed our plan in carrying out this action.

-Ad-libbed action/Not an ad-libbed action.

Environmental Turbulence

New Measure

Seven-point Likert scale, where 1 is none and 7 is a lot. When the action was taken, how would you rate the level of change in the following areas? (change is defined as any deviation from the status quo):

-Within your team.

-Within your firm.

-Within external sources (customers, suppliers, distributors)

Organizational Real-time Flows

New Measure

Seven-point Likert scale, where 1 is none and 7 is a lot.

Of information received from this source, how much was

face-to-face, phone, or e-mail:

-Team members.

Organizational Memory

Adapted from

Moorman and Miner (1997)

Seven-point Likert scale, where 1 is disagree and 7 is agree.

For this action, my team has:

-well-defined procedures.

-a standard approach.

-a great deal of knowledge.

-strong skills.

\section{Product Effectiveness Outcomes}

Seven-point Likert scale, where 1 is a negative effect and 7 is a positive effect.

This action has or is likely to have the following effect on:

a. Design effectiveness.

New Measure

-Product design

-Product performance

b. Market Effectiveness.

Driven, in part,

-Product sales

- Customer acceptance

-General success of the product

Process Effectiveness Outcomes

Seven-point Likert scale, where 1 is a negative effect and 7 is a positive effect.

This action has or is likely to have the following effect on:

a. Cost efficiency.

Driven, in part,

-Product costs

b. Time efficiency.

-Length of project development process

-Speed of product development process

-Project timeliness

c. Team functioning.

- Team commitment level

New Measure

-Team functioning

-Team enthusiasm

d. Team learning

-The way we think about the project

New Measure

- Our certainty level

- Our understanding level

- How much we have learned
Moorman (1995)

\section{REFERENCES}

Aaker, David A. (1988), Strategic Market Management, 2d ed. New York: John Wiley \& Sons.

$\rightarrow$ Anderson, Paul F. (1982), "Marketing, Strategic Planning, and the Theory of the Firm," Journal of Marketing, 46 (Spring), 15-26.

Andrews, Jonlee and Daniel C. Smith (1996), "In Search of the Marketing Imagination: Factors Affecting the Creativity of Marketing Programs for Mature Products," Journal of Marketing Research, 33 (May), 174-87.

Argyris, Chris and Donald Schön, (1978), Organizational Learning: A Theory of Action Perspective. Reading, MA: Addison-Wesley.

$\rightarrow$ Armstrong, J. Scott (1982), "The Value of Formal Planning for Strategic Decisions: Review of Empirical Research," Strategic Management Journal, 3 (July/September), 197-211.

Arnold, Hugh H. (1982), "Moderator Variables: A Clarification of Conceptual, Analytic, and Psychometric Issues," Organizational Behavior and Human Performance, 29 (April), 43-175.

Bagozzi, Richard P. (1994), "Structural Equation Models in Marketing Research: Basic Principles," in Principles of Marketing Research, Richard P. Bagozzi, ed. Cambridge, MA: Blackwell, 317-84.
Bailey, Derek (1980), Improvisation: Its Nature and Practice in Music. Ashbourne, Derbyshire, Great Britain: Moorlan Publishing Co. Ltd.

$\rightarrow$ Barley, Stephen R. (1986), "Technology as an Occasion for Structuring: Evidence from Observations of CT Scanners and the Social Order of Radiology Departments," Administrative Science Quarterly, 31 (March), 78-108.

Bastien, David T. and Todd J. Hostager (1988), "Jazz as a Process of Organizational Innovation," Communication Research, 15 (5), 582-602.

and (1992), "Cooperation as Communicative Accomplishment: A Symbolic Interaction Analysis of an Improvised Jazz Concert," Communication Studies, 43 (Summer), 92-104.

Berliner, Paul F. (1994), Thinking in Jazz: The Infinite Art of Improvisation. Chicago: University of Chicago Press.

Bjurwill, Christer (1993), "Read and React: The Football Formula," Perceptual and Motor Skills, 76 (June), 1383-86.

$\rightarrow$ Borko, Hilda and Carol Livingston (1989), "Cognition and Improvisation: Differences in Mathematics Instruction by Expert and Novice Teachers," American Educational Research Journal, 26 (Winter), 473-98. 
Boyd, Harper W., Jr. and Orville C. Walker Jr. (1990), Marketing Management: A Strategic Approach. Homewood, IL: Richard D. Irwin Inc.

- - - and Jean-Claude Larréché (1998), Marketing Management: A Strategic Approach with a Global Orientation, 3d ed. Boston: Irwin/McGraw-Hill.

$\rightarrow$ Brown, Shoma L. and Kathleen M. Eisenhardt (1995), "Product Development: Past Research, Present Findings, and Future Directions," Academy of Management Review, 20 (April), 343-78.

$\rightarrow$ Burgelman, Robert A. (1983), "A Process Model of Internal Corporate Venturing in the Diversified Major Firm," Administrative Science Quarterly, 28 (June), 223-44.

$\rightarrow-$ (1994), "Fading Memories: A Process Theory of Strategic Business Exit in Dynamic Environments," Administrative Science Quarterly, 39 (March), 24-56.

Campbell, David (1989), "An Introduction to Nonlinear Dynamics," in Lectures in the Sciences of Complexity: XIII-XXII, Daniel L. Stein, ed. Redwood, CA: Addison-Wesley.

Cohen, Jacob and Patricia Cohen (1983), Applied Multiple Regression/Correlation Analysis for Behavioral Sciences. Hillsdale, NJ: Lawrence Erlbaum Associates.

$\rightarrow$ Cohen, Michael D. (1991), "Individual Learning and Organizational Routine: Emerging Connections," Organization Science, 2 (February), 135-39.

and Paul Bacdayan (1994), "Organizational Routines Are Stored as Procedural Memory: Evidence from a Laboratory Study," Organization Science, 4 (November), 554-68.

— James G. March, and Johan Olson (1972), "A Garbage Can Model of Organizational Choice," Administrative Science Quarterly, 17 (March), 1-25.

$\rightarrow$ Cohen, Wesley M. and Daniel A. Levinthal (1990), "Absorptive Capacity: A New Perspective on Learning and Innovation," Administrative Science Quarterly, 35 (March), 128-52.

Cooper, Robert G. and Elko J. Kleinschmidt (1986), “An Investigation into the New Product Process: Steps, Deficiencies, and Impact," Journal of Product Innovation Management, 3 (June), 71-85.

and _ (1987), "New Products: What Separates Winners from Losers," Journal of Product Innovation Management, 4 (3), 169-84.

Cossé, Thomas J. and John E. Swan (1983), "Strategic Marketing Planning by Product Managers-Room for Improvement," Journal of Marketing, 47 (Summer), 92-102.

Cravens, David W. and Charles W. Lamb Jr. (1993), Strategic Marketing Management Cases, 4th ed. Homewood, IL: Richard D. Irwin Inc.

Crossan, Mary and Marc Sorrenti (1997), "Making Sense of Improvisation," in Advances in Strategic Management, Vol. 14, James P. Walsh and Ann Huff, eds. Greenwich, CT: JAI Press, 155-80.

Cyert, Richard M. and James G. March ([1963] 1992), A Behavioral Theory of the Firm, 2d ed. Oxford: Blackwell.

Dalrymple, Douglas J. and Leonard J. Parsons (1990), Marketing Management: Strategy and Cases, 5th ed. New York: John Wiley \& Sons.

Day, George (1990), Market-Driven Strategy. New York: The Free Press.

- (1994), "The Capabilities of Market-Driven Organizations," Journal of Marketing, 58 (October), 37-52.

_ and Prakash Nedungadi (1994), "Managerial Representations of Competitive Advantage," Journal of Marketing, 58 (April), 31-44.

_ and Robin Wensley (1983), "Marketing Theory with a Strategic Orientation," Journal of Marketing, 47 (Fall), 79-89.

Deshpandé, Rohit, John U. Farley, and Frederick E. Webster Jr. (1993), "Corporate Culture, Customer Orientation, and Innova- tiveness in Japanese Firms: A Quadrad Analysis," Journal of Marketing, 52 (January), 23-36.

$\rightarrow-$ and Frederick E. Webster Jr. (1989), "Organizational Culture and Marketing: Defining the Research Agenda," Journal of Marketing, 53 (January), 3-15.

Dickson, Peter R. (1997), Marketing Management, 2d ed. New York: The Dryden Press.

$\rightarrow$ Dougherty, Deborah (1992), "Interpretive Barriers to Successful Product Innovation in Large Firms," Organization Science, 3 (May), 179-202.

Egge, Eric (1986), "Motivating Buyer Actions," American Salesman, 31 (August), 24-27.

$\rightarrow$ Eisenhardt, Kathleen M. (1989), "Making Fast Strategic Decisions in High-Velocity Environments," Academy of Management Journal, 32 (September), 543-76.

- and Behnam N. Tabrizi (1995), “Accelerating Adaptive Processes: Product Innovation in the Global Computer Industry," Administrative Science Quarterly, 40 (March), 84-110.

Etzioni, Amitai (1964), Modern Organizations. Englewood Cliffs, NJ: Prentice Hall.

Galbraith, Jay (1973), Designing Complex Organizations. Reading, MA: Addison-Wesley.

Gioia, Theodore (1988), The Imperfect Art. New York: Oxford University Press.

$\rightarrow$ Granovetter, Mark (1973), "The Strength of Weak Ties," American Journal of Sociology, 78 (May), 1360-80.

$\rightarrow-$ (1985), "Economic Action and Social Structure: The Problem of Embeddedness," American Journal of Sociology, 91 (November), 481-510.

Griffin, Abbie (1997), "The Effect of Project and Process Characteristics on Product Development Cycle Time," Journal of Marketing Research, 34 (February), 24-35. and Albert L. Page (1993), "An Interim Report on Measuring Product Development Success and Failure," Journal of Product Innovation Management, 10 (September), 291-308.

and - (1996), "PDMA Success Measurement Project: Recommended Measures for Product Development Success and Failure," Journal of Product Innovation Management, 13 (November), 478-96.

Hatch, Mary Jo (1997), "Jazzing Up the Theory of Organizational Improvisation," Advances in Strategic Management, Vol. 14, James P. Walsh and Ann Huff, eds. Greenwich, CT: JAI Press, 181-91.

Holbrook, Morris B. (1995), Consumer Research: Introspective Essays on the Study of Consumption. Thousand Oaks, CA: Sage Publications.

$\rightarrow$ Huber, George P. (1991), "Organizational Learning: The Contributing Processes and the Literatures," Organizational Science, 2 (February), 88-115.

- and Reuben R. McDaniel (1986), "Decision-Making Paradigm of Organizational Design," Management Science, 32 (May), 572-89.

$\rightarrow$ Hutchins, Edwin (1991), "Organizing Work by Adaptation," Organization Science, 2 (February), 14-39.

$\rightarrow$ Hutt, Michael D., Peter H. Reingen, and John R. Ronchetto Jr. (1988), "Tracing Emergent Processes in Marketing Strategy Formation," Journal of Marketing, 52 (January), 4-19.

Imai, Ken-ichi, Ikujiro Nonaka, and Hirotaka Takeuchi (1985), "Managing the New Product Development Process: How Japanese Companies Learn and Unlearn," in The Uneasy $\mathrm{Al}$ liance, K.B. Clark, R.H. Hayes, and C. Lorenz, eds. Cambridge, MA: Harvard University Press, 337-81.

Irby, David M. (1992), "How Attending Physicians Make Instructional Decisions when Conducting Teaching Rounds," Academic Medicine, 67 (10), 630-38. 
$\rightarrow$ Ittner, Christopher and David F. Larcker (1997), "Product Development Cycle Time and Organizational Performance," Journal of Marketing Research, 34 (February), 13-33.

Jain, Subhash C. (1997), Marketing Planning and Strategy, 5th ed. Cincinnati: South-Western College Publishing.

$\rightarrow$ Jaworski, Bernard J. and Ajay K. Kohli (1993), "Market Orientation: Antecedents and Consequences," Journal of Marketing, 57 (July), 53-71.

Kerin, Roger A. and Robert A. Peterson (1995), Strategic Marketing Problems: Cases and Comments, 7th ed. Englewood Cliffs, NJ: Prentice Hall.

$\rightarrow$ Kohli, Ajay K., and Bernard J. Jaworski (1990), “Market Orientation: The Construct, Research Propositions, and Managerial Implications," Journal of Marketing, 54 (April), 1-18.

Kotler, Philip (1994), Marketing Management: Analysis, Planning, Implementation, and Control, 8th ed. Englewood Cliffs, NJ: Prentice Hall.

Lehmann, Donald R. and Russell S. Winer (1994), Product Management. Boston: Richard D. Irwin Inc.

$\rightarrow$ Leonard-Barton, Dorothy (1992), "Core Capabilities and Core Rigidities: A Paradox in Managing New Product Development," Strategic Management Journal, 13 (Summer), 111-25.

Levi-Strauss, Claude (1967), The Savage Mind. Chicago: University of Chicago Press.

$\rightarrow$ Levitt, Barbara and James G. March (1988), "Organizational Learning," Annual Review of Sociology, 14, 319-40.

Lovell, Jim and Jeffrey Kluger (1995), Apollo XIII. New York: Simon and Schuster Inc.

Mangham, Iain L. (1986), Power and Performance in Organizations: An Exploration of Executive Process. Oxford: Basil Blackwell.

March, James G. (1976), "The Technology of Foolishness," in Ambiguity and Choice in Organizations, James G. March and Johan P. Olsen, eds. Norway: Universitetsfarlgt, 69-81.

- (1991), "Exploration and Exploitation in Organizational Learning," Organization Science, 2 (February), 71-78.

and Herbert A. Simon (1958), Organizations. New York: John Wiley \& Sons.

Menzel, M. (1981), "Interpersonal and Unplanned Communications: Indispensable or Obsolete?" in Biomedical Innovation, E.B. Roberts et al., eds. Cambridge, MA: MIT Press, 155-63.

$\rightarrow$ Miller, Chet C. and Laura B. Cardinal (1994), "Strategic Planning and Firm Performance: A Synthesis of More than Two Decades of Research," Academy of Management Journal, 37 (6), 1649-65.

$\rightarrow$ Miner, Anne S. (1987), “Idiosyncratic Jobs in Formalized Organizations," Administrative Science Quarterly, 32 (September), 327-51.

$\rightarrow-$ (1990), "Structural Evolution Through Idiosyncratic Jobs: The Potential for Unplanned Learning," Organization Science, 1 (2), 195-210.

—, Christine Moorman, and Paula Bassoff (1997), “Organization Improvisation in New Product Development," Market Science Institute Report No. 97-110. Cambridge, MA: Marketing Science Institute.

Mintzberg, Henry (1994), The Rise and Fall of Strategic Planning. New York: The Free Press.

_ (1996), “Learning 1, Planning 0," California Management Review, 38 (Summer), 92-93.

- and Alexandra McHugh (1985), "Strategic Formation in an Adhocracy," Administrative Science Quarterly, 30 (June), 160-97.

- , Richard T. Pascale, Michael Goold, and Richard P. Rumelt (1996), "The 'Honda Effect' Revisited," California Manage ment Review, 38 (Summer), 78-117.

Montoya-Weiss, Mitzi M. and Roger Calantone (1994), "Determinants of New Product Performance: A Review and Meta-
Analysis," Journal of Product Innovation Management, 11 (November), 397-417.

$\rightarrow$ Moorman, Christine (1995), "Organizational Market Information Processes: Cultural Antecedents and New Product Outcomes," Journal of Marketing Research, 32 (August), 318-35.

— and Anne S. Miner (1995), "Walking the Tightrope: Improvisation and Information Use in New Product Development," Marketing Science Institute Report No. 95-101. Cambridge, MA: Marketing Science Institute.

and - (1997), "The Impact of Organizational Memory on New Product Performance and Creativity," Journal of Marketing Research, 34 (February), 91-107.

- and - (1998), "Organizational Improvisation and Organizational Memory," Academy of Management Review, forthcoming.

Nonaka, Ikujiro (1990), "Redundant, Overlapping Organization: A Japanese Approach to Managing the Innovation Process," California Management Review, 32 (Spring), 27-38.

Olson, Eric M., Orville C. Walker, and Robert W. Ruekert (1995), "Organizing for Effective New Product Development: The Moderating Role of Product Innovativeness," Journal of Marketing, 59 (January), 48-62.

Pascale, Richard T. (1984), "The Honda Effect," excerpted from "Perspectives on Strategy: The Real Story Behind Honda's Success," California Management Review, 26 (Spring), $47-72$.

(1996), "Reflections on Honda," California Management Review, 38 (Summer), 112-17.

Pedhazur, Elazar J. (1982), Multiple Regression in Behavioral Research: Explanation and Prediction. New York: Holt, Rinehart, and Winston Inc.

Peter, J. Paul and James H. Donnelly Jr. (1998), Marketing Management: Knowledge and Skills, 5th ed. Boston: Irwin/McGraw-Hill.

Pfeffer, Jeffrey (1982), Organizations and Organization Theory. New York: Putnam.

Pressing, Jeff (1984), "Cognitive Processes in Improvisation," in Cognitive Processes in the Perception of Art, W.R. Crozier and A.J. Chapman, eds. Amsterdam: North-Holland, 345-63. (1988), "Improvisation: Methods and Models," in Generative Processes in Music: The Psychology of Performance, Improvisation, and Composition, John A. Sloboda, ed. Oxford: Oxford University Press, 129-78.

Preston, Alistair (1991), "Improvising Order," in Organization Analysis and Development, I.L. Mangham, ed. New York: John Wiley \& Sons.

Quelch, John A., Robert J. Dolan, and Thomas J. Kosnik (1993), Marketing Management: Text and Cases. Homewood, IL: Richard D. Irwin Inc.

Quinn, James B. (1980), Strategies for Change: Logical Incrementalism. Homewood, IL: Richard D. Irwin Inc.

- (1986), "Innovation and Corporate Strategy: Managed Chaos," in Technology in the Modern Corporation: A Strategic Perspective, Mel Horwich, ed. New York: Pergamon Press, 167-83.

Robins, Fred (1991), "Marketing Planning in the Large Family Business," Journal of Marketing Management, 7 (October), 325-41.

Rogers, Everett (1983), The Diffusion of Innovations. New York: The Free Press.

Scott, Richard W. (1987), Organizations: Rational, Natural, and Open Systems, 2d ed. Englewood Cliffs, NJ: Prentice Hall.

$\rightarrow$ Sinha, Deepak K. (1990), "The Contribution of Formal Planning to Decisions," Strategic Management Journal, 11 (6), 479-92.

$\rightarrow$ Sinkula, James M. (1994), "Market Information Processing and Organizational Learning," Journal of Marketing, 58 (January), $35-45$. 
$\rightarrow$ Solomon, Larry (1986), "Improvisation II," Perspectives of New Music, 24 (2), 224-35.

$\rightarrow$ Song, Z. Michael and Mark E. Parry (1997), "The Determinants of Japanese New Product Successes," Journal of Marketing Research, 34 (February), 64-76.

Spolin, Viola (1963), Improvisation for the Theater: A Handbook of Teaching and Directing Techniques. Evanston, IL: Northwestern University Press.

Sproull, Lee and Sara Keisler (1991), Connections: New Ways of Working in the Networked Organization. Cambridge, MA: MIT Press.

Sutton, Howard (1990), Marketing Planning. New York: The Conference Board.

$\rightarrow$ Tushman, Michael and Phillip Anderson (1986), "Technological Discontinuities and Organizational Environments," Administrative Science Quarterly, 31 (September), 439-65.

$\rightarrow$ Van de Ven, Andrew H. (1986), "Central Problems in the Management of Innovation," Management Science, 32 (May), 590-607.

(1993), "Managing the Process of Organizational Innovation," in Organizational Change and Redesign, George P. Huber and William H. Glick, eds. Cary, NC: Oxford University Press, 269-94.

$\rightarrow$ Walker, Orville C., Jr., and Robert W. Ruekert (1987), "Marketing's Role in the Implementation of Business Strategies," Journal of Marketing, 51 (July), 15-33.

$\rightarrow$ Walsh, James P. (1995), "Managerial and Organizational Cognition: Notes from a Trip Down Memory Lane," Organization Science, 6 (May-June), 280-321.

$\rightarrow-$ and Gerardo Rivera Ungson (1991), "Organizational Memory," Academy of Management Review, 16 (January), 57-91.
Weick, Karl E. (1979), The Social Psychology of Organizing, 2d ed. Reading, MA: Addison-Wesley.

(1987), "Substitutes for Strategy," in The Competitive Challenge: Strategies for Industrial Innovation and Renewal, David J. Teece, ed. New York: Harper and Row, 221-33.

(1993a), "The Collapse of Sensemaking in Organizations: The Mann Gulch Disaster," Administrative Science Quarterly, 38 (December), 628-52.

(1993b), "Organizational Redesign as Improvisation," in Organizational Change and Redesign, George P. Huber and William H. Glick, eds. Cary, NC: Oxford University Press, 346-79.

(1993c), "Managing as Improvisation: Lessons from the World of Jazz," working paper, University of Michigan Graduate School of Business Administration.

(1996), "Drop Your Tools: An Allegory for Organizational Studies," Administrative Science Quarterly, 41 (June), 301-13.

Williamson, Oliver E. (1975), Markets and Hierarchies: Analysis and Antitrust Implications. New York: The Free Press.

$\rightarrow$ Wind, Jerry and Vijay Mahajan (1997), "Issues and Opportunities in New Product Development: An Introduction to the Special Issue," Journal of Marketing Research, 34 (February), 1-11.

$\rightarrow-$ and Thomas S. Robertson (1983), "Marketing Strategic: New Directions for Theory and Research," Journal of Marketing, 47 (Spring), 12-25.

Winter, Sidney G. (1987), "Knowledge and Competence as Strategic Assets," in The Competitive Challenge: Strategies for Industrial Innovation and Renewal, David J. Teece, ed. New York: Harper and Row, 159-85.

Zaltman, Gerald, Robert Duncan, and Jonny Holbek (1973), Innovations and Organizations. New York: John Wiley \& Sons. 